\title{
Hubungan Anemia pada Kehamilan Dengan Inpartu Kala II Lama di BPM Ny. Suhariyati Surabaya
}

\author{
Ratna Ariesta Dwi Andriani \\ Fakultas Keperawatan dan Kebidanan \\ Universitas Nahdlatul Ulama Surabaya J1. Smea 57 Surabaya \\ Email: ratnariesta@unusa.ac.id
}

\begin{abstract}
Relations of Anemia in Pregnancy With Inpartu Kala II Lama in BPM Ny. Suhariyati Surabaya. Anemia in pregnancy in Indonesia is still high, with a national rate of $65 \%$ which each region has different variations, anemia is one of the causes of prolonged labor. BPM Ny. Suhariyati Surabaya in December 2014 of 18 people inpartu obtained $6(33.33 \%)$ who have anemia, of the 63 occurred prolonged second stage and 12 persons $(66.7 \%)$ were not anemic, of the 12 people 3 people experiencing prolonged second stage. The purpose of this study was to determine the relationship between maternal anemia during long inpartu the second stage in the BPM Ny. Suhariyati Surabaya. This study uses an observational analytic study design and by the time the study was cross sectional study with a research population is all women berslin in BPM Ny. Suhariyati a total of 90 people for 2 months. Selection of the sample by simple random sampling with a large sample studied was 40 . The variables in this study are anemic pregnant women and old stage II. At the time of data collection procedures inpartu using primary data and the processing of data by cross tables and chi square test. Based on the results of the study of 40 people found $14(35.00 \%)$ had anemia which consists of 4 people (28.57\%) had stage II normal and 10 (71.42\%) experienced a prolonged second stage. The conclusions of this study is almost half inpartu mothers have anemia, mostly mothers inpartu experiencing prolonged second stage and there is a relationship between maternal anemia during inpartu with prolonged second stage. Advice for pregnant women should undergo hemoglobin levels every 3 months and taking 90 tablets Fe to pregnant women during pregnancy.
\end{abstract}

Abstrak: Hubungan Anemia pada Kehamilan Dengan Inpartu Kala II Lama di BPM Ny. Suhariyati Surabaya. Anemia pada kehamilan di Indonesia masih tinggi, dengan angka nasional $65 \%$ yang setiap daerah mempunyai variasi berbeda, anemia merupakan salah satu penyebab partus lama. Di BPM Ny. Suhariyati pada Desember 2014 dari 18 orang inpartu didapatkan 6 orang $(33,33 \%)$ yang memiliki anemia, dari 6 orang tersebut 3 orang terjadi kala II lama dan dari 12 orang $(66,7 \%)$ tidak anemia, dari 12 orang tersebut 3 orang mengalami kala II lama. Tujuan penelitian ini adalah mengetahui hubungan antara anemia ibu hamil pada saat inpartu dengan lama kala II di BPM Ny. Suhariyati. Penelitian ini menggunakan desain penelitian analitik observasional dan menurut waktu penelitian merupakan penelitian Cross Sectional dengan populasi penelitian adalah semua ibu berslin di BPS Ana Susanti sejumlah 90 orang selama 2 bulan. Pemilihan sampel secara simple random sampling dengan besar sampel yang diteliti adalah 40 orang. Variabel dalam penelitian ini yaitu anemia ibu hamil dan lama kala II. Pada saat inpartu prosedur 
pengumpulan data menggunakan data primer dan pengolahan data dengan cara tabel silang serta uji chi square.Berdasarkan hasil penelitian dari 40 orang didapatkan 14 orang $(35,00$ $\%)$ memiliki anemia yang terdiri dari 4 orang $(28,57 \%)$ mengalami kala II normal dan 10 orang $(71,42 \%)$ mengalami kala II lama. Simpulan penelitian ini adalah hampir setengahnya ibu inpartu memiliki anemia, sebagian besar ibu inpartu mengalami kala II lama dan terdapat hubungan antara anemia ibu hamil pada saat inpartu dengan kala II lama. Saran bagi ibu hamil sebaiknya melakukan pemeriksaan kadar $\mathrm{Hb}$ tiap 3 bulan sekali dan meminum 90 tablet Fe kepada ibu hamil selama masa kehamilan.

Kata Kunci : Anemia Ibu Hamil, Lama Kala II

\section{PENDAHULUAN}

Salah satu indikator pembangunan di bidang kesehatan adalah Angka Kematian Ibu (AKI) dan Angka Kematian Bayi (AKB). Angka Kematian Ibu di Indonesia masih tinggi sebesar 228/100.000 kelahiran hidup (SDKI tahun 2007). Di Jawa Timur, Badan Pusat Statistik (BPS) mencatat Angka Kematian Ibu tahun 2005 yaitu 262/100.000 kelahiran hidup. Target yang harus dicapai pada tahun 2010 untuk AKI sebesar 125/100.000 kelahiran hidup dengan cara mengurangi penyebab tidak langsung, seperti anemia $51 \%$ dan nifas $45 \%$ (SDKI, 2002-2003, periode Agustus 2005).

Di seluruh dunia frekuensi anemia dalam kehamilan cukup tinggi, berkisar antara 10-20 \%. Karena defisiensi makanan memegang peranan yang sangat penting dalam timbulnya anemia, maka dapat dipahami bahwa frekuensi itu lebih tinggi lagi di negeri-negeri yang sedang berkembang, dibandingkan dengan negeri-negeri yang sudah maju. Menurut penyelidikan Hoo Swie Tjiong frekuensi anemia dalam kehamilan setinggi 18,5\%, pseudo anemia 57,9 \% (Wiknjosastro, 2007).
Menurut Buku Acuan Nasional Pelayanan Kesehatan Maternal dan Neonatal (2001 : 281) anemia didalam kehamilan bila kondisi ibu dengan kadar $\mathrm{Hb}$ di bawah $11 \mathrm{gr} \%$ pada trimester I dan III atau kadar kurang dari 10,5 gr \% pada trimester II, nilai batas tersebut dan perbedaannya dengan kondisi wanita tidak hamil terjadi karena hemodilusi, terutama pada trimester II. Menurut WHO kejadian anemia hamil berkisar antara 20-89 \% dengan menetapkan $\mathrm{Hb}$ 11 gr \%. Angka anemia kehamilan di Indonesia cukup tinggi yaitu angka anemia kehamilan 3,8\% pada trimester I, $13,6 \%$ pada trimester II, dan $24,8 \%$ pada trimester III (Manuaba, 2007). Sedangkan bertambahnya volume darah dalam kehamilan sudah mulai sejak kehamilan umur 10 minggu dan mencapai puncaknya dalam kehamilan antara 32 dan 36 minggu (Wiknjosastro, 2007).

Bentuk anemia pada kehamilan dapat digolongkan menjadi: anemia defisiensi besi $62,3 \%$, anemia megaloblastik $29,0 \%$, anemia hipoplastik $8,0 \%$ dan anemia hemolitik 0,7\% (Wiknjosastro, 2007).

Anemia mengurangi daya tahan tubuh ibu dalam menghadapi infeksi, mengurangi prestasi kerja, meninggikan 
frekuensi infeksi pada kehamilan dan persalinan, meninggikan resiko kematian maternal, angka prematuritas, kematian perinatal, serta perdarahan antepartum dan post partum.

Menurut Manuaba I.B.G (2001 : 91) menjelaskan bahwa angka anemia pada ibu hamil di Indonesia kurang lebih $67 \%$ sekitar 10-15\% tergolong anemia berat yang mempengaruhi tumbang janin dalam rahim. Dilihat dari proses persalinan dan kelahiran merupakan kejadian fisiologis yang normal. Kelahiran seorang bayi juga merupakan peristiwa sosial yang ibu dan keluarganya nantikan selama 9 bulan. Ketika persalinan dimulai peran ibu adalah untuk melahirkan bayinya. Peran petugas adalah memantau persalinan untuk mendeteksi dini adanya komplikasi.

Persalinan dan kelahiran normal adalah proses pengeluaran janin yang terjadi pada kehamilan cukup bulan (37-42 minggu), lahir spontan dengan presentasi belakang kepala yang berlangsung 18 jam, tanpa komplikasi baik pada ibu maupun pada janin (Winkjosastro, 2007). Kala II dimulai dari pembukaan lengkap $(10 \mathrm{~cm})$ sampai bayi lahir. Proses ini biasanya berlangsung 2 jam pada primi dan 1 jam pada multi (Syaifudin dkk.,2002). Kala II lama adalah persalinan ringan pembukaan serviks lengkap ibu mengejan tetapi tidak ada kemampuan penurunan (Saifuddin, AB, 2001). Partus yang lama apabila tidak segera di akhiri akan menimbulkan kelelahan pada ibu, dehidrasi, infeksi rahim, perlukaan jalan lahir, gawat janin sampai kematian karena asfiksia dalam rahim (Pedoman Diagnosis dan Terapi Lab/UPF Ilmu Kebidanan dan Penyakit Kandungan, 1994).
Anemia dalam kehamilan memberi pengaruh kurang baik pada ibu, baik pada kehamilan, persalinan maupun nifas. Berbagai penyakit dapat timbul akibat anemia, seperti abortus, partus prematurus, hambatan tumbuh kembang janin dalam rahim, gangguan his, partus lama karena inersia uteri, perdarahan post partum karena atonia uteri, syok infeksi baik intrapartum serta anemik yang berat (Hb $<69 / 100 \mathrm{ml})$ dapat menyebabkan decompensasi cordis (Winkjosastro, 2007).

\section{METODE}

Desain penelitian ini adalah analitik observasional. Penelitian ini bersifat Cross Sectional, artinya peneliti melakukan observasi in partu kala II pada ibu hamil dengan anemia.

Penelitian ini dilakukan di BPM Ny. Suhariyati, pada bulan Januari - Mei 2015. Besar sampel yang digunakan adalah sebanyak 40 responden.

Data dikumpulkan menggunakan data primer yaitu melalui pemeriksaan kadar Hemoglobin darah ibu inpartu dan diikuti sampai waktu pembukaan $10 \mathrm{~cm}$ dan menghitung lama kala II dan data sekunder menggunakan rekam medik.

Instrumen yang digunakan dalam penelitian ini adalah alat bantu berupa $\mathrm{Hb}$ Sahli sebagai alat ukur kadar Hemoglobin, partograf, dan lembar pengumpul data.

Data yang terkumpul dianalisis dengan menggunakan uji statistik $C h i$ Kuadrat yaitu dengan tingkat kemaknaan $\mathrm{p} \leq 0,05$, artinya $\mathrm{H}_{0}$ ditolak yang berarti ada Hubungan Antara Anemia Ibu Hamil Pada Saat Inpartu dengan Lama Kala II. 
Dalam penelitian ini, keterbatasan yang dihadapi oleh peneliti adalah Waktu penelitian yang sangat singkat.

\section{HASIL DAN PEMBAHASAN}

a. Hasil

1. Anemia ibu hamil saat inpartu

Tabel 1. Distribusi Responden

Berdasarkan Anemia ibu hamil pada saat inpartu di BPM Ny. Suhariyati bulan Januari sampai Mei 2015

\begin{tabular}{lcc}
\hline $\begin{array}{l}\text { Anemia ibu } \\
\text { hamil pada } \\
\text { saat Inpartu }\end{array}$ & Jumlah & $\begin{array}{c}\text { Prosentase } \\
\%\end{array}$ \\
\hline Anemia & 14 & 35 \\
Tidak & 26 & 65 \\
\hline Jumlah & 40 & 100 \\
\hline \multicolumn{3}{c}{ Sumber : Data Primer 2015 }
\end{tabular}

\section{Lama Kala II Persalinan}

Tabel 2. Distribusi Repsonden

Berdasarkan Lama Kala II Persalinan di BPM Ny. Suhariyati bulan Januari sampai Mei 2015

\begin{tabular}{lcc}
\hline $\begin{array}{c}\text { Lama Kala II } \\
\text { Persalinan }\end{array}$ & Jumlah & $\begin{array}{c}\text { Prosent } \\
\text { ase } \%\end{array}$ \\
\hline Kala II normal & 22 & 55 \\
Kala II lama & 18 & 45 \\
\hline Jumlah & 40 & 100
\end{tabular}

Sumber : Data Primer 2015

3. Anemia Ibu Hamil pada saat Inpartu

Tabel 3. Distribusi Tabel Silang Anemia ibu hamil pada saat inpartu dan Lama Kala II Persalinan di BPS Ngatmiati Bangah Gedangan Sidoarjo bulan Maret sampai April 2015

\begin{tabular}{|c|c|c|c|c|c|c|}
\hline \multirow{3}{*}{$\begin{array}{l}\text { Anemia ibu } \\
\text { hamil saat } \\
\text { inpartu }\end{array}$} & \multicolumn{5}{|c|}{ Lama Kala II } & \multirow{3}{*}{$\begin{array}{c}\text { Jumlah } \\
\% \\
\end{array}$} \\
\hline & \multicolumn{2}{|c|}{$\begin{array}{c}\text { Kala II } \\
\text { Normal }\end{array}$} & \multicolumn{3}{|c|}{ Kala II Lama } & \\
\hline & $\mathrm{N}$ & $\%$ & $\mathrm{~N}$ & $\%$ & $\mathrm{~N}$ & \\
\hline Tidak & 18 & 69,23 & 8 & 30,76 & 26 & 100 \\
\hline Anemia & 4 & 28,57 & 10 & 71,42 & 14 & 100 \\
\hline Jumlah & 22 & & 18 & & 40 & \\
\hline
\end{tabular}

Berdasarkan hasil uji chi square $\mathrm{x}^{2}=$ 4,54 > 3,84 maka $\mathrm{H}_{0}$ ditolak yang artinya terdapat hubungan antara anemia ibu hamil pada saat inpartu dengan lama kala II.

\section{b. Pembahasan}

\section{Anemia Ibu Hamil Saat Inpartu}

Pada tabel 1. dapat dilihat bahwa dari 40 responden 14 responden $(35 \%)$ mengalami anemia. Angka ini cukup besar untuk kejadian anemia saat proses persalinan. Menurut Manuaba (2001) anemia pada kehamilan di Indonesia masih tinggi dengan angka nasional $65 \%$ dengan perbedaan pada wilayah masingmasing, hal ini disebabkan karena volume darah bertambah banyak yang dimulai dari umur kehamilan 8 minggu sampai persalinan dengan puncak penurunan kadar hemoglobin pada usia kehamilan 32-36 minggu. Menurut Syaifuddin, 2002 anemia didalam kehamilan bila kondisi ibu dalam kadar $\mathrm{Hb}$ dibawah 11,95\% pada trimester I dan II atau kadar kurang dari 10.5 gr \% pada trimester II. Nilai batas tersebut dan perbedaannya dengan kondisi wanita tidak hamil terjadi karena hemodilusi, terutama trimester II.

Di masyarakat pada umumnya jika seorang wanita dinyatakan hamil maka banyak sekali pantangan terhadap makanan tertentu yang mana di dalam makanan tersebut mengandung zat besi yang dapat meningkatkan kadar hemoglobin dalam darah ibu hamil, serta efek samping dari tablet Fe seperti pusing, mual, sulit buang air besar membuat ibu hamil enggan untuk meminum tabel $\mathrm{Fe}$ secara teratur hal inilah yang membuat masih tingginya angka kejadian anemia. 


\section{Lama Kala II Persalinan}

Dari hasil penelitian pada tabel 2 . dapat diketahui bahwa angka kejadian kala II lama cukup besar yaitu dari 40 responden, 18 responden $(45 \%)$ memiliki kala II lama. Menurut Mochtar, 1998 dalam buku Sinopsis obstetri Jilid I bahwa lama kala II dipengaruhi oleh beberapa faktor yaitu jalan lahir, janin, tenaga atau kekuatan, psikis ibu penolong. Persalinan lama adalah his tidak efisien (adekuat), faktor janin (mal presentasi, malposisi, janin besar), faktor jalan lahir yaitu panggul sempit, kelainan serviks, vagina dan tumor. (Syaifuddin dkk, 2001).

Salah satu faktor dari lama kala II adalah faktor tenaga dari ibu, kekuatan ibu meneran merupakan tenaga yang utama untuk mengeluarkan janin dari jalan lahir dan pimpinan persalinan yang benar sangat menentukan lamanya kala II persalinan. Terlebih lagi jika ibu dalam keadaan anemia maka akan mempengaruhi lama kala II.

3. Hubungan Anemia Ibu Hamil saat Inpartu dengan Lama Kala II

Pada tabel 3 dari 18 orang ibu yang memiliki kadar hemoglobin rendah (anemia), sebagian besar responden $(71,42 \%)$ mengalami kala II lama. Kadar hemoglobin ibu inpartu berpengaruh pada lama Kala II persalinan, pada kadar hemoglobin rendah dapat menyebaban gangguan his primer dan sekunder, gangguan kekuatan mengejan, terjadi partus terlantar, dapat terjadi kelelahan, data sering memerlukan tindakan, operasi kebidanan, Kala III diikuti dengan retensio plasenta dan perdarahan karena atonia uteri (Manuaba, 1998). Sedangkan menurut Winkjosastro (2007) anemia dalam kehamilan memberi pengaurh kurang baik pada ibu, baik pada kehamilan, persalinan maupun nifas. Berbagai penyakit dapat timbul akibat anemia, seperti abortus, paritas prematuris, gangguan his. Partus lama karena inersia uteri, penderita post partum karena atonia uteri.

Menurut pedoman diagnosis dan terapi Lab/UPF Ilmu Kebidanan dan Penyakit Kandungan (1994), persalinan lama disebabkan karena faktor panggul yaitu kesmepitan panggul, faktor anak yaitu kelainan letak dan anak besar, faktor tenaga yaitu Hipotonia dan kelainan mengejan, faktor penolong yaitu pimpinan yang salah. Kadar hemoglobin normal diperlukan dalam proses persalinan untuk tenaga melahirkan bayi dan mencegah terjadi kala II lama (Wirakusumah, 1999). Kadar hemoglobin normal mengoptimalkan fungsi darah sebagai pembawa oksigen untuk disalurkan keseluruh tubuh, maka tubuh tidak akan cepat lelah, lemah letih lesu muka akan tampak lebih cerah dan kinerja tubuh akan meningkat (Wirakusuma, 1999).

Pada waktu persalinan dibutuhkan kadar hemoglobin yang optimal untuk menghadapi proses persalinan. Kadar hemoglobin dalam darah ibu inpartu berpengaruh pada keadaan tubuh ibu agar tidak lelah dan letih sedangkan Kala II persalinan sangat membutuhkan kekuatan mengejan dari ibu. Kadar hemoglobin yang rendah membuat tubuh ibu menjadi lemah dan letih sehingga mengganggu kekuatan mengejan ibu sehingga berpengaruh pada lama kala II. Maka terdapat hubungan antara kadar hemoglobin ibu inpartu dengan lama kala II persalinan.sangat membutuhkan kekutan mengejan dari ibu. 


\section{SIMPULAN}

1. Ibu inpartu di BPM Ny. Suhariyati hampir setengahnya memiliki anemia.

2. Ibu inpartu di BPM Ny. Suhariyati mengalami Kala II lama namun jika tidak mendapat penanganan yang tepat dapat menimbulkan komplikasi pada ibu dan janin.

3. Terdapat hubungan antara anemia ibu hamil pada saat ibu inpartu dengan lama kala II persalinan di BPM Ny. Suhariyati.

\section{DAFTAR PUSTAKA}

Depkes RI. 2000. Buku Standar Playanan Kebidanan. Jakarta

Dorland, Newman. 2002. Kamus Kedokteran Dorland. Jakarta : EGC Guyton, Arthur C. 2007. Buku Ajar Fisiologi Kedokteran. Jakarta : EGC

Manuaba, IBG. 2007. Ilmu Kebidanan, Penyakit Kandungan dan Kleuarga Berencana Untuk Pendidikan Bidan. Jakarta : EGC

Notoatmodjo, $\quad$ Soekidjo. 2005. Metodologi Riset Keperawatan. Jakarta : CV. Agung Seto

Nursalam dan Pariani. 2000. Pendekatan Praktik Metodologi Riset Keperawatan. Jakarta : CV. Infomedika , 2001. Pendekatan Praktis Metodologi Riset Keperawatan. Jakarta : CV. Agung Seto

Nursalam, 2003. Konsep dan Penerapan Metodologi Penelitian Ilmu Keperawatan, Pedoman Skripsi, Tesis, dan Instrumen Penelitian Keperawatan. Jakarta
Obstetri Pathologi, 1984. Bagian Obstetri dan Ginekologi. Bandung : FK. Universitas Padjajaran.

Prajitno, Prabowo. 1994. Pedoman Diagnosisi dan Therapy Lab/UPF Ilmu Kebidanan dan Penyakit Kandungan. RSUD Dr. Soetomo Surabaya

Prawirohardjo. 2001. Buku Acuan Nasional Layanan Kesehatan Maternal dan Neonatal. Jakarta : Yayasan Bina Pustaka Sarwono Prawirohardjo

Purnawan Junaidi 1982. Kapita Selekta Kedokteran. Jakarta : Media Aesculapius FKUI

Rustam, Mochtar. 2011. Edisi 3 Jilid I Sinopsis Obstetri. Jakarta : EGC

Saifuddin, Abdul Bari. 2002. Buku Acuan Nasional Pelayanan Kesehatan Maternal dan Neonatal. Jakarta : Yayasan Bina Pustaka Sarwono Prawirohardjo

Sediaoetama, Achma Djaeni. 1999. Ilmu Gizi Jilid II. Jakarta : Dian Rakyat

Soedjanah. 2002. Metode Statistika. Bandung : Tarsito

Winkjosastro, Hanifa. 2007. Ilmu Kebidanan. Jakarta : Yayasan Bina Pustaka Sarwono Prawirohardjo

Wirakusumah, Emma.1999. Perencanaan Menu Anemia Gizi bayi. Jakarta : Pustaka Pembangunan Swadaya Nusantara 